levels. At a simple level, MacIntyre's work, especially After Virtue, has had a strong influence on all areas of applied ethics in the past decade. In bioethics, the resurgence of virtue ethics as a viable way of approaching dilemmas of both doctors and patients, stems from MacIntyre's assertion that we must revisit the narrative unity of the moral life. But at a deeper level, we need to think through the basic issues in metaethics raised by Fuller's juxtapositioning of Rorty and Fuller. Bioethics is as prone to uncertainty about the roots of moral value as any other area of ethics, but there has been a tendency for the literature to avoid these moral abstract discussions, perhaps out of fear of losing the attention of the busy practitioner who asks for answers, not more questions. The discipline will descend into mere pragmatics if such issues are never debated, or if current assumptions are left unchallenged. (For example, the publication of the second edition of Engelhardt's Foundations of Bioethics provides an ideal opportunity to question the assumptions about personal and social morality in that approach to bioethics.) Thus Making Sense of MacIntyre can be strongly commended to all readers of this journal. Though medicine is never mentioned, the questions the book explores are fundamental for anyone interested in establishing a viable medical ethics in our pluralistic and confused age.

ALASTAIR V CAMPBELL

Centre for Ethics in Medicine,

University of Bristol

\section{Am I My Brother's Keeper? The Ethical Frontiers of Biomedicine}

\author{
Arthur L Caplan, Bloomington and \\ Indiana, Indiana University Press, \\ 1998, 241 pages, £20. 99(hb).
}

During the last few years there has been a modest backlash against the ethics of unlimited patient autonomy. In this volume Caplan has produced a strong challenge to the emphasis on personal freedom, thus signalling the end of biomedicine's endorsement of a laissez faire, individualist approach to the ethics of health care. The appeal to personal autonomy developed in response to a lack of trust in doctors and a questioning of the grounds for their paternalism. Patient autonomy was frequently endorsed as a means of curtailing over-treatment, especially with regard to the end-stages of life. But the reality of modern medicine, with its emphasis on cost-containment and rationing, would suggest that lack of trust in the medical profession is rooted in fears of under-treatment. Moreover, as Caplan observes, trust is unlikely to be restored in the context of proposals to limit therapy with reference to criteria based on the patient's alleged lifestyle, and even less likely will the economically marginalised find good reason to trust health carers if they are offered the freedom to purchase therapy in return for organ "donation".

The nineteen essays in this volume combat self interest and moral cynicism, stressing the virtue of trust and of caring and sharing the burdens of disability and dying. The topics covered here embrace some of the more complex moral questions of recent biomedicine, which include: fertility treatment; the ethics of medical research; doctor-assisted suicide; access to health care; eugenics; cloning; analogies with the holocaust; organ transplants; payment for organs and tissues; living donors; xenografts; rationing of health care, and proposals to redefine death. A central theme is the desire to combat the morality of an unfettered free market and unlimited self-determination. For example, the opening essay on infertility treatment and artificial conception questions the value placed on individual choice as a supreme justification for reproduction, whether naturally or artificially mediated. Caplan draws attention to numerous scandals associated with several infertility clinics involving the mishandling of embryos; lack of quality control; inadequately tested therapies; health and safety violations, and inadequate screening of potential patients, where greed has supplanted the morally commendable motive of assisting the infertile to have babies.

A similar picture is painted of practices associated with treatment at the end-stages of life, which reveal that motives other than respect for selfdetermination operate. The case for legally assisted suicide, argues Caplan, is not so much based on desire for self-determination but in response to fear, guilt, cost, loss of dignity and, above all, loss of trust in one's doctors. Trust is essentially compromised, argues Caplan, when doctors are seen as protectors of the nation's purse, when they embrace the duty to consider the fiscal consequences of care. If it is believed that decisions to withhold therapy are based on imperatives to ration resources then scepticism will accompany the doctor's pronouncement of medical futility. Futility has been widely discussed in recent years and Caplan's response to the "futilitarians" is linked to his plea for the restoration of trust, and recognition of the moral authority of doctors to say "enough is enough".

The need to regain trust is echoed in Caplan's discussion of proposals to redefine death. Following a review of various philosophically grounded arguments in favour of redefining death Caplan insists that the strongest case against their public acceptability is based on evidence of lack of trust in medicine brought on by "shifts in the structure and financing of health care" (page 135). This theme is pursued in the essays which deal with health care rationing. Caplan is primarily concerned with the US experience of health care in recent years and despite several references to case studies from Europe, the book is primarily written from an American standpoint. Yet years of costcontainment policies in the UK, together with an escalation of malpractice scandals, have nevertheless contributed to a similar breakdown of trust in the providers of health care. If Caplan's account of the underlying problems facing health care is correct - and I believe that it is - then the restoration of public confidence in medicine must involve drawing an acceptable line somewhere between zealous advocacy of a patient's best interests and guardianship of economic resources. For the obvious casuality of the present system is public trust in the medical profession. "Virtues", says Caplan, "do not thrive in bottom-line, profit-oriented markets" (page 146).

DAVID LAMB University of Birmingham

\section{Altruism, Society, Health Care}

Edited by Anders Nordgren and Claes-Goran Westrin, Uppsala, Uppsala University, 1998, 90 pages, SEK142 (sc).

This short volume contains five papers on altruism which were presented at a symposium at the University of Uppsala, along with an introduction and a 
concluding summary. Nordgren and Westrin begin their collection by referring to a recent paradigm shift within a number of disciplines which involves a recognition of the existence of altruism and an interest in understanding it. The diversity of the collection is splendid, with perspectives drawn from psychology, Darwinian theory, economics and biomedical ethics as well as public health. But, for me, this same diversity has made the collection as a whole unsatisfying even though it contains some accomplished essays. In a longer book, and perhaps one written after the experience of sharing these papers, there would have been scope for dialogue and debate to open up the substantive and epistemological conflicts and resonances between the various perspectives.

As it stands the collection is multidisciplinary rather than interdisciplinary. The authors not only occupy different theoretical frameworks and ask rather different questions but they also work with significantly different conceptions of altruism.

Some of the contributors are concerned with operationalising and measuring altruism. For them it is part of the tool-kit of social and experimental psychology, and has to be defined as precisely as possible and independently of the evaluative dimensions of ordinary usage. Here there is a tendency to start with the reductionist egoism - altruism dichotomy and to look for ways to define these terms and to detect the differences between them. C Daniel Batson reports on his ingenious experiments to discern people's "underlying motivation", rather than their merely instrumental goals, and on his discovery of "genuine altruism" in his experimental subjects. At the end of his paper he is careful to explain that, in addition to egoism and altruism, there are other forms of "prosocial motivation" including what he labels collectivism ("not me or thee but we") and principlism. Batson thereby limits the label altruism to cases in which the "underlying motive" is to benefit others rather than to cases where motivation encompasses, or results in, the wellbeing of others.

By contrast Thomas Murray, in what I see as the most successful and insightful contribution, starts by rejecting "the simplistic dichotomy between self-interest and altruism" in favour of "the complexity of motivations we seem to find in actual human cultures". His is a discussion of gift-giving between both friends and strangers, and includes an exploration of analogies between Trobriand Islanders' customs and practices and those of modern health care systems in general, and the practices of blood and organ donation in particular. But his analysis and celebration of solidarity, and of the ways in which we are motivated to affirm our relationships and not just our selves, is perhaps closer to what Batson describes as collectivism: “... humans are often self-seeking, to be sure, but ... they must attend to the needs of others. In doing so, they also contribute to their own flourishing. Whether we choose to call that altruism is not so important" (page 77).

What both of these authors share is the advocacy, albeit in different terms, of more complex models of motivation than those which underlie many currents in both social science and policy-making. Indeed one of the clear themes in the volume is a scepticism about "homo economicus" and the increasing influence of associated market models in Western European health policy. Through their scepticism these papers point to an important research programme which is beyond the scope of this collection: there is a need to map the models of motivation, and the assumptions about specific motivations, that underpin health care policies and practices and to seek to understand how certain forms of motivation are produced, sustained or inhibited. Most urgently, there is a need to challenge public policies which are based on simple assumptions about self-interested motivation, as these assumptions have the potential to be harmful as well as misguided.

In this connection it is worth reading Anthony Culyer's excellent piece, Altruism and economics. Here Culyer makes it clear that economics as a discipline can deal with more complex accounts of motivation than is implied by some uses of "homo economicus", and reminds us that, for example, a picture of agents as utility maximisers should not be equated with a picture of agents as selfish. Of course agents only pursue things which they regard as valuable. It is this which facilitates the all too common charge of universal egoism. Yet valued things can be very different; they can be more or less individualistic and - in most useful senses of the term - more or less self-seeking.

ALAN CRIBB

Centre for Public Policy Research, King's College London

\section{IVF in the 90s.} Towards a Medical, Social and Ethical Evaluation

Edited by E Hildt and D Mieth, Aldershot, Hants, Ashgate Publishing, 1998, 370 pages, $£ 45$ (hc).

Some books are more frustrating read than others, and read one mus one is committed to write a comme for the fournal of Medical Ethics. Fruso trating because the potential for much is there, and the sum total is wanting. One must admit, howeve् that the sub-title, Towards a Medic Social and Ethical Evaluation, does not necessarily lead the reader to expect a conclusion on the subject matter. This book concerns IVF and its cons quences, especially from the point (Bf view of "the particular connectie with genetic diagnosis and therape (this being the remit of this European Commission supported endeavour).O

But does this book accomplish tasks? When evaluating, one must 1. some foundations, some plan of actiog and this is where the frustration lie One feels strongly that an analysis, the extraction of the spirit of the contribs tions by the editors would have made completely different book. The preface does not attempt any such analysis, and introduces the subject by a mete listing. Worse, to a specialist in the field, it makes the strange stateme that the success rate of IVF has been challenged compared with the occus rence of spontaneous pregnancy, when in fact the editors probably refer toa paper comparing unexplained infertifity of relatively short duration and value of fertility treatments in general challenge anyone to explain to me hof a woman with surgically irremediable tubal damage may conceive withou IVF bar a miracle. It would be too eass to highlight the scientific inaccuracies which sprinkle the text of some contrib butions. This is not my purpose here

It must be stressed, however, the such bad communication between different disciplines may be at the core of what is described by $\mathbf{P}$ van Tongere霜 as the "antagonism" he often observe between scientists and ethicists. Th differs from my personal experience as a clinician who teaches ethics to her medical students, and who thus ma claim to have feet in both camps.

Indeed they should not be seen camps, especially for the practitione amongst us, but as overlapping fields in 